\title{
Analyzing the muddles of analysis: (some of) what analytic theologians can learn from the history of analytic feminism
}

Rutledge, J. C.

\begin{tabular}{|c|c|}
\hline Date of deposit & $10 / 05 / 2019$ \\
\hline Document version & Author's accepted manuscript \\
\hline Access rights & $\begin{array}{l}\text { (C) } 2019 \text { John Wiley \& Sons Ltd. This work is made available online } \\
\text { in accordance with the publisher's policies. This is the author } \\
\text { created, accepted version manuscript following peer review and } \\
\text { may differ slightly from the final published version. }\end{array}$ \\
\hline $\begin{array}{l}\text { Citation for } \\
\text { published version }\end{array}$ & $\begin{array}{l}\text { Rutledge, J. C. (2019). Analyzing the muddles of analysis: (some } \\
\text { of) what analytic theologians can learn from the history of } \\
\text { analytic feminism. Modern Theology }\end{array}$ \\
\hline $\begin{array}{l}\text { Link to published } \\
\text { version }\end{array}$ & https://doi.org/10.1111/moth.12525 \\
\hline
\end{tabular}

Full metadata for this item is available in St Andrews Research

Repository at: https://research-repository.st-andrews.ac.uk/

\section{St Andrews Research Repository}




\section{Analyzing the Muddles of Analysis \\ (Some of) What Analytic Theologians Can Learn from the History of Analytic Feminism}

Abstract: Analytic theologians have ironically experienced difficulties in precisely defining the meaning of 'analytic' with respect to their style of theology. In this paper, we turn to the history of a similar research project, analytic feminism, to see how it went about defining 'analytic' in relation to the typically non-analytic subject area of feminist studies. We then consider two commonly referred

to attempts to define analytic theology, one methodological and the other socio-historical, and discuss shortcomings of each. I close with a new definition of analytic theology that aims to incorporate all the insights in the discussions which precede it.

This is an exploratory and constructive essay concerning the short histories of two recent movements, both of which emerged from the conviction that the work of analytic philosophy could helpfully contribute to, though by no means supplant, the current state of things in their respective disciplines. These two disciplines have come to be known as analytic feminism and analytic theology, and although their contents do sometimes converge, I am not concerned in this essay with considering that shared content. Rather, in this paper I have two primary goals: (i) to review the history of analytic feminists and their attempts to dialogue with other feminists who expressed concern over the importation of analytic methods into feminist studies, and (ii) to offer a new definition of analytic theology in light of the lessons learned from this very short history of analytic feminism.

Despite recent attempts to define analytic theology ${ }^{1}$, there remains no consistent consensus as to what the phenomenon is. The thesis of this essay, then, is that the process of defining analytic feminism instructs the process of defining analytic theology. ${ }^{2}$

My thesis in this paper is, I suppose, rather minimal. It is that there is much for analytic theologians to gain from attending to the way in which analytic feminists have sought to build bridges

${ }^{1}$ Here are several: (i) Oliver D. Crisp, “Analytic Theology," The Expository Times 122, no. 10 (2011): 469-477; (ii) Kevin Timpe, “On Analytic Theology," Scientia et Fides 3, no. 2 (2015): 9-22; (iii) Thomas H. McCall, An Invitation to Analytic Christian Theology (Downers Grove, IL: IVP Academic, 2015); (iv) William J. Abraham, "Systematic Theology as Analytic Theology", in Analytic Theology: New Essays in Philosophical Theology, eds. by Oliver D. Crisp and Michael C. Rea (Oxford: Oxford University Press, 2009), 54-69. Two other examples with which I significantly interact in a later section of this article are (v) Michael C. Rea, "Introduction," in Analytic Theology: New Essays in Philosophical Theology, eds. by Oliver D. Crisp and Michael C. Rea (Oxford: Oxford University Press, 2009), 1-30 and (vi) William Wood, "Analytic Theology as a Way of Life," Journal of Analytic Theology 2 (2014): 43-60. Rea's discussion is technically one concerning a characterization of analytic philosophy in service of characterizing analytic theology.

${ }^{2}$ I am grateful to an anonymous referee for encouraging me to put this more strongly and offering a suggested rewording. 
with and learn from their non-analytic colleagues. The precise contents of what I think is important in this history will reveal itself throughout my discussion, but for now, allow me to tell you how I plan to proceed.

I begin in $\$ 1$ with a discussion of some features, both historical and methodological, about the analytic feminist movement. These features include some early objections to the importation of the analytic philosophical method into feminism (e.g. that it exhibits male-bias, promotes a problematic value-neutrality, assumes that individuals are interchangeable and fundamental, and champions a worrying optimism about the existence of and our ability to gain epistemic access to pure objectivity), followed by responses from some of those members of the movement. After summarizing a few salient points from this non-exhaustive history of analytic feminism, I turn to the question of defining analytic theology (in \$2). There have been some recent attempts at definitions, some of which are methodological and some of which are more loosely defined by historical associations (e.g. with particular academic journals or historical figures in mind). I offer some worries about- these definitions. The methodological ones, it seems, tend toward definitions which are too narrow, excluding certain projects from the family of analytic theology which clearly are analytic theology, and the historical ones seem to leave methodological content too much to one side. Lastly, in $\$ 3$, I compile some desiderata for a good definition of analytic theology, drawing from the discussions of the previous two sections and conclude with a provisional definition of my own.

\section{Analytic Feminism in Relation to Feminism and Analytic Philosophy}

Although dating the beginning of feminism generally is not a straightforward process, it is clear that academic feminism (i.e. in the sense of feminism explicitly identified as such in higher education academic institutions) began developing in the 1960s. Indeed, by the 1970s, such noteworthy figures as Alison Jaggar, Marilyn Frye, Joyce Trebilcot and, just a bit later, Helen Longino and Sandra Harding, were already engaged in feminist scholarship from an analytic background. ${ }^{3}$

Despite the presence of some analytic scholars in the early days of feminism, it would be a significant understatement to note that the number of such scholars was small. Around 1990, however, practitioners of analytic philosophy who possessed a keen interest in the aims of feminism became concerned that they needed a way of identifying both with the feminist movement and their analytic philosophical heritage. The analytic method clearly brought with it some methodological differences from mainstream feminist perspectives, and thus, a label which highlighted this methodological distinctiveness would help its proponents to avoid misunderstandings. For this reason, among many

\footnotetext{
${ }^{3}$ This isn't an exhaustive list, but one should see (i) Alison Jaggar, "Political Philosophies of Women's Liberation," in Feminism and Philosophy, eds. Mary Vetterling-Braggin, Frederick A. Elliston, and Jane English (Totowa, NJ: Rowman and Littlefield, 1977), 5-21; (ii) Marilyn Frye, The Politics of Reality: Essays in Feminist Theory (Crossing Press, 1983); Joyce Trebilcot, Mothering: Essays in Feminist Theory (New Feminist Perspectives) (Lanham, MD: Rowman \& Littlefield Publishers, 1983); (iv) Sandra Harding, The Science Question in Feminism (Ithaca, NY: Cornell University Press, 1986); (v) Helen E. Longino, "Science, Objectivity, and Feminist Values," Feminist Studies 14 (1988): 561-74.
} 
others, the Society for Analytical Feminism (SAF) was formed and has since boasted a premier lineup of top-flight analytic philosophers as members, including Virginia Klenk, the founder and first president of SAF, and Ann E. Cudd, who together edited a volume of the journal Hypatia in 1995 dedicated exclusively to issues in analytic feminism. ${ }^{4}$

But what were those distinctives of analytic feminism that worried more traditional feminists? Although there were a number of objections, the central ones were these: analytic methods (i) were hopelessly masculinist ${ }^{5}$, (ii) naively assumed the existence of a pure objective reality to which we have value-neutral epistemic access ${ }^{6}$, and (iii) operated as if the agents of concern for their various projects (e.g. the agents involved in defining knowledge) could be unproblematically represented as unlocated, disembodied, and autonomous individuals (e.g. as if one's gender identity or personal background made no difference about either what one could know or whether one satisfied the various conditions of knowledge). ${ }^{7}$ Let us explore these criticisms and analytic responses to them in a bit more detail.

First, to say that analytic philosophy was hopelessly masculinist was to say that the analytic method was intrinsically disinterested in, or resistant to, various feminist values. Indeed, these concerns could be identified rather readily when attending to many assumed views in philosophy; for instance, that the emotional realm was to be identified as distinctly feminine along with the thesis that emotion was irrational. Or, for another example from the philosophy of economics, that an unhindered form of capitalism in our society would result in pareto optimality for all, and that such a result was a good thing, even without considering which sorts of people (whether divided up by gender, race, sexuality, economic status, age, amount of education, etc.) would be the best off in such conditions. These sorts of concerns were worrying to feminists of both analytic and non-analytic persuasions.

\footnotetext{
${ }^{4}$ Ann E. Cudd and Virginia Klenk, Hypatia: A Journal of Feminist Philosophy, 10, no. 3 (1995).

${ }^{5}$ Consider, for instance, (i) Jane Duran, Toward a Feminist Epistemology (Savage, MD: Rowman and Littlefield, 1995): 108-110; (ii) Genevieve Lloyd, The Man of Reason: "Male" and "Female" in Western Philosophy (Minneapolis, MN: University of Minnesota Press, 1984): 103-110; or (iii) Merrill B. Hintikka and Jaakko Hintikka, "How Can Language be Sexist?" in Discovering Reality: Feminist Perspectives on Epistemology, Metaphysics, Methodology, and Philosophy of Science, eds. by Sandra Harding and Merrill B. Hintikka (New York: Kluwer Academic Publishers, 1983), 139-148.

${ }^{6}$ For example, consider Janice Moulton, “A Paradigm of Philosophy: The Adversary Method," in Discovering Reality: Feminist Perspectives on Epistemology, Metaphysics, Methodology, and Philosophy of Science, eds. by Sandra Harding and Merrill B. Hintikka (New York: Kluwer Academic Publishers, 1983), 149-164. ${ }^{7}$ E.g. (i) Naomi Scheman, Engenderings: Constructions of Knowledge, Authority, and Privilege (New York: Routledge, 1993) and (ii) Alison Jaggar, Feminist Politics and Human Nature (Totowa, NJ: Rowman and Allanheld, 1983). For an attack on the universal "S knows that p" model of epistemology that informs my example here see Lorraine Code, What Can She Know?: Feminist Theory and the Construction of Knowledge (Ithaca, NY: Cornell University Press, 1991). For the source of my list of inadequacies in analytic philosophy from a feminist perspective see the excellent Stanford Encyclopedia of Philosophy article: Ann Garry, "Analytic Feminism," in The Stanford Encyclopedia of Philosophy, ed. Edward Zalta (2012), https://plato.stanford.edu/entries/femapproach-analytic/\#FemCriAna.
} 
In response to the presence of male-bias in analytic philosophy, analytic feminists took a number of approaches. To begin, they conceded that there was no denying the presence of much male-bias in philosophy, just as there was no denying its presence in, for example, the history of scientific research. Nevertheless, they argued that male-bias was not essential to the analytic method and, moreover, that much of contemporary analytic philosophy had become more self-aware concerning those biases to the point of eliminating many of them (though, of course, by no means all). ${ }^{8}$ And in addition, many analytic feminists responded to this charge by producing their own analytic work on traditional analytic topics as examples of analytic philosophy well-attuned to feminist values. ${ }^{9}$ Thus, it became clear that the analytic method characterizing their work simply could not be charged as intrinsically masculinist and thereby incompatible with feminism.

The second common objection sometimes lodged against practitioners of the analytic method was this: analytic methods express too much optimism about our epistemic access to objective reality and lack sufficient skepticism of the existence of such a reality in the first place. The worry as often expressed seemed to rest on a notion of social construction applied to all of reality. It would begin with the less controversial claim that "race, gender, and sexuality are socially constructed" to the very controversial claim that social construction goes "all the way down," such that everything from truth, knowledge, rationality, identity, nature, and reality itself could be thought to depend on us for its existence. ${ }^{10}$

The responses to this sort of worry have, of course, varied from analytic feminist scholar to analytic feminist scholar. Some, such as Sally Haslanger, argued that while some social construction may very well characterize our world, the presence of some social construction does not inevitably explode into all reality. Moreover, others, such as Martha Nussbaum, argued that these constructivist attacks on objectivity and rationality undermined feminist interests, and they did so because critiquing those with whom one disagrees requires holding to traditional views of objectivity and rationality; that

\footnotetext{
${ }^{8}$ For examples of such developments with respect to the two examples above-i.e. concerning first, the emotions, rationality, and the feminine and second, gender-inattentive capitalist economics-see especially Sarah Coakley, God, Sexuality, and the Self (Cambridge: Cambridge University Press, 2013) and Ann E. Cudd and Nancy Holmstrom, Capitalism, For and Against: A Feminist Debate (Cambridge: Cambridge University Press, 2011).

${ }^{9}$ See especially Louise M. Antony and Charlotte Witt, A Mind of One's Own: Feminist Essays on Reason and Objectivity, $2^{\text {nd }}$ Edition (Boulder, CO: Westview, 2001) that exams the bias paradox. According to this phenomenon, there is an apparent inconsistency in criticizing male-bias because it is bias. The inconsistency arises insofar as the feminist critique of male-bias is itself a bias. Antony argues that bias is not itself the problem, but rather, that some biases preclude perception of truth in better or worse ways than other biases.

${ }^{10}$ Sally Haslanger, “Ontology and Social Construction,” Philosophical Topics 23, no. 2 (1995): 96. See Nancy Fraser, Unruly Practices (Minneapolis: University of Minnesota Press, 1989) for this sort of social constructionist perspective.
} 
is, views which are required to make those critiques intelligible. ${ }^{11}$ In other words, on such a response, the analytic method was not so much "overly optimistic" as it was operating out of a sort of practical and theoretical necessity.

What of the worry that disembodied and disinterested individual agents were non-negotiable constituents of the method of analytic philosophy? What precisely was the concern? Primarily, this objection to the analytic method rested on a neglect of the importance of groups (e.g. the insights of groups as delineated by some form of standpoint epistemology, according to which one's epistemic standpoint or perspective might be relevant to what sorts of things one knows or can know).

In response to this charge, many feminist works were produced illustrating the fit of embodied agents in analytic-style thinking. ${ }^{12}$ As a result, it was clear that the complaint did not characterize analytic thinking as such, but rather, it merely characterized some forms of analytic thinking from the past. Moreover and notably, in contemporary work, the centrality of social metaphysics and social epistemology in mainstream analytic philosophy has further demonstrated that the charge of excessive individualism simply can no longer be plausibly maintained against all practitioners of the analytic method.

So, what can we say by way of summary concerning this very concise and non-exhaustive history of analytic feminism? First, we can see that analytic feminism arose out of a context in which its practitioners saw a need for social cohesion, both among feminists broadly and among those feminists that found themselves trained in and enamored with much of what analytic philosophy had to offer. They wanted feminist thought to influence analytic philosophy as well as analytic philosophy to be put to use in achieving the ends of feminist thought. And as a result, they coined the term 'analytic feminism' to clarify their methodological and ideological aims as a whole.

Second, in responding to characteristic concerns regarding the analytic method from their feminist colleagues, analytic feminists demonstrated the compatibility of analytic philosophy with (i) disparate views concerning what the precise tools of analytic philosophy were supposed to be; (ii) a recognition of social groups as fundamental to various theoretical pursuits (e.g. the search for a definition of rationality); (iii) an elevation of embodied experience as part and parcel of analytic methodology; and (iv) a significant degree of social construction that might inform various philosophical and feminist concepts.

Now, before moving onto a survey of some attempts to define analytic theology, allow me to conclude this section with the definition of analytic feminism provided by Anne Cudd. ${ }^{13}$ There, she writes,

Analytic feminism applies analytic concepts and methods to feminist issues and applies feminist concepts and insights to issues that traditionally have been of interest to

${ }^{11}$ Cf. Martha Nussbaum, "Feminism and Philosophy: Review of Louise Antony and Charlotte Witt, eds., a Mind of One's Own," The New York Review of Books 41, no. 17 (1994): 59-63.

${ }^{12}$ E.g. Code, What Can She Know? and Virginia Held, Justice and Care: Essential Readings in Feminist Ethics (Boulder, CO: Westview, 1995).

13 Ann E. Cudd, "Analytic Feminism," in Encyclopedia of Philosophy, $2^{\text {nd }}$ Edition, ed. by Donald M. Borchert (Farmington Hills, MI: Thomson Gale Publishing, 2006), 157. 
analytic philosophers. Analytic feminists, like analytic philosophers more generally, value clarity and precision in argument and use logical and linguistic analysis to help them achieve that clarity and precision. Unlike nonfeminists, they write against a background of recognition of sexism (practices that take women and feminine things to be inferior to men and masculine things) and androcentrism (practices that take males or men or men's life experiences to be the norm or the ideal for human life), and work with the aim of contesting both.

Analytic feminism holds that the best way for scholars to counter sexism and androcentrism in their work is through forming a clear conception of and pursuing truth, logical consistency, objectivity, rationality, justice, and the good, while recognizing that these notions have often been perverted by androcentrism throughout the history of philosophy. Analytic feminists engage the literature traditionally thought of as analytic philosophy, but also draw on other traditions in philosophy, as well as work by feminists working in other disciplines, especially the social and biological sciences.

For anyone familiar with the literature surrounding analytic theology, the parallels between attempts to define it and the above definition of analytic feminism are striking. Allow us, then, to turn to the question of defining analytic theology in a way that can ultimately appropriate the insights of this discussion of analytic feminism.

\section{Defining Analytic Theology}

Perhaps in attempting to understand the best way to define analytic theology, it would be helpful to begin with Michael Rea's now standard description of analytic philosophy. This is not a definition per se, but it nevertheless helps us identify some of the pitfalls of adopting a methodological approach to defining analytic theology. Here are the five prescriptions he gives for someone practicing analytic philosophy:

P1. Write as if philosophical positions and conclusions can be adequately formulated in sentences that can be formalized and logically manipulated.

P2. Prioritize precision, clarity, and logical coherence.

P3. Avoid substantive (non-decorative) use of metaphor and other tropes whose semantic content outstrips their propositional content.

P4. Work as much as possible with well-understood primitive concepts, and concepts that can be analyzed in terms of those.

P5. Treat conceptual analysis (insofar as it is possible) as a source of evidence. ${ }^{14}$

In the interest of conserving space, I will not focus on each of these prescriptions. There are reasons for anyone, theologian or philosopher, to voice concerns over many of these prescriptions.

\footnotetext{
${ }^{14}$ Oliver D. Crisp and Michael C. Rea, Analytic Theology: New Essays (Oxford: Oxford University Press, 2009).
} 
For instance, the explicit restriction of the "use of metaphor[s]... whose semantic content outstrips their propositional content" might strike some theologians as precluding all God-talk in virtue of the analogous nature of whatever we might like to say about God. These are indeed important concerns, but if there is good reason from just one of these prescriptions to think that methodological definitions (such as we are treating Rea's prescriptions now) are inescapably fraught with problems in virtue of being methodological, then we have reason to worry about any methodological definition, no matter its content. ${ }^{15}$ Thus instead of criticizing each of them, let us focus our attention on (P2).

Most analytic philosophers looking at (P2) probably think of it as the least controversial of these prescriptions. After all, who could fault anyone for aiming to write with perspicuity and consistency? One reason to worry, of course, would be because clarity and precision seem relatively subjective. What is clear to me because it is placed in logical notation, for instance, would likely be unintelligible to anyone lacking experience working in, say, standard first-order logic. Moreover, including clarity and precision as an explicit prescription in analytic methodology might misleadingly encourage someone to infer that the analytic method is committed to the claim that alternative methods deny (P2); that is, we might infer from (P2)'s inclusion on this list that non-analytics are imprecise, unclear, and worst of all, logically incoherent. For those reasons alone, I would be inclined to leave (P2) out of a methodological definition of analytic method, but even these complaints are not, I think, the only ones telling against (P2)'s adequacy.

Consider the final characteristic of (P2); that is, logical coherence. Given the inclusion of the word 'logical' here, it is natural to think that by 'coherence' Rea must be thinking of something like logical consistency. And we should think of logical consistency as a property possessed by a set of sentences. Accordingly, a set of sentences is logically consistent (on this way of thinking) if, and only if, it is possible for all those sentences to be true. But now, consider the following set of sentences which should be familiar to anyone working in Christian theology:

1. Christ is mutable (in virtue of Christ's human nature)

2. Christ is immutable (in virtue of Christ's divine nature)

3. Christ is both mutable and immutable (from 2 and 3$).{ }^{16}$

This argument consists of a set of classically inconsistent sentences. That is, if we assume the adequacy of classical logic for assessing the entailment relations which hold between these sentences, then we see that they cannot possibly all be true. That is, they are ruled out, or at least seem to be ruled out, as permissible affirmations of those who would affirm (P2), on its current interpretation.

${ }^{15} \mathrm{I}$ am supposing that such reasons are defeasible. So, (P2) provides more of a caution in utilizing methodological definitions.

${ }^{16}$ J. C. Beall, "Christ - A Contradiction: A Defense of Contradictory Christology," Journal of Analytic Theology (forthcoming): 2. A copy of a pre-publication version of this article is available on Beall's website at http://entailments.net/papers/xtology.pdf. All citations and page numbers of Beall are from this version of the article. 
Indeed, this argument has led a number of philosophical theologians ${ }^{17}$ to think of admirably creative, even ingenious, ways of affirming the first two premises listed here without fear of contradiction. That is, they seem to be motivated by a desire to affirm premises (1) and (2) in a logically consistent (i.e. non-contradictory) manner.

But suppose some systematic theologian were to look at these sentences and think to herself, "Why all the fuss from the philosophical theologians here? We do not need to avoid the contradiction. I mean, claims that follow from the hypostatic union probably just do involve contradictions! So instead of wasting time avoiding the contradiction, we should just embrace it as true." This claim is bound to strike many of us as bizarre, but the point should be seriously considered rather than brushed off. Is there good reason, other than strong intuition, to build the impermissibility of contradictions into the analytic method? (No, there is not ${ }^{18}$. But moreover, would theology even be amenable to such a restriction since there, if anywhere, we would be less surprised to learn of true contradictions? (Theology should resist the restriction as a requirement, and here is why).

As J. C. Beall has pointed out, to build the impermissibility of contradictions into the methodology of analytic theology presupposes a problematic account of logic itself. ${ }^{19}$ The classical account of logic assumed above has its relevant domains (e.g. mathematics), but it simply cannot account for such mundane phenomena as we find in ordinary language-e.g. vagueness, liar paradoxes, etc.- or the more eccentric phenomena of quantum mechanics. To take just one illustration from philosophy of language, consider the predicate, '...is bald' as used in the sentence, 'Sir Patrick Stewart is bald'. One assumption of classical logic states that for any predicate, like '...is bald', it is always either true of something or it is false of something but not both true and false of that thing. But surely the truth conditions of the predicate '... is bald' are not so straightforward. There are borderline cases for which our use of the term 'bald' does not permit us to accurately say someone is bald or not bald. That is, there are some cases where the satisfaction conditions of baldness are not well-defined, and so, we might most accurately say of some people that they are neither bald nor notbald (but perhaps something in between). How unsurprising would it be, then, to think that classical

${ }^{17}$ For instance, see Timothy Pawl, In Defense of Conciliar Christology: A Philosophical Essay (Oxford: Oxford University Press, 2016) or Marilyn McCord Adams, Christ and Horrors (Cambridge, Cambridge University Press, 2006). An anonymous reviewer also brought my attention to the following helpful article which summarizes much of the current literature in analytic Christology: James Arcadi, "Recent Developments in Analytic Christology," Philosophy Compass 13, no. 4 (2018): e12480. https://doi.org/10.1111/phc3.12480.

${ }^{18}$ Indeed, as pointed out by an anonymous referee, theologians have been occupied with the project of demonstrating the logical coherence of doctrines like those found in Christology far longer than the life of analytic theology understood as a movement.

${ }^{19}$ Specifically, Beall, "Christ - A Contradiction," 13 highlights his Exhaustion and Exclusion principles as the culprits. The former states, "every model is 'exhaustive' with respect to every predicate in the sense that every object in the domain is either in $G^{+}$or in $G$ " and the latter states, "every model is 'exclusive' with respect to every predicate in the sense that no object in the domain is in both $G^{+}$or in $G^{-}$." 
logic might fail to accommodate not only our ordinary linguistic practices but also a theological reality supposedly occupied by the source of the entire created realm?

It is not the purpose of this section to defend a theology that boasts the existence of true contradictions. ${ }^{20}$ The point of the above reflections on the possibility of such a contradictory theology, however, has been to illustrate that (P2)'s affirmation of logical coherence, if understood as logical consistency, must not assume the adequacy of classical logic to the theological task. Rather, whatever sort of coherence is included, it must be a coherence shaped by its object of enquiry; that is, it should be a logic determined by theology rather than a theology determined by one's logic. ${ }^{21}$

But then, if we do not understand (P2)'s affirmation of logical coherence as logical consistency classically construed, what does it add to the prescriptions Rea has already provided? (P1) already tells us that the analytic method makes use of logic, whatever sort of logic is adopted. And if by "write in a logically coherent way" Rea meant the weaker claim, "write in such a way that what you say is intelligible," then it would not seem to add anything to the methodological definition beyond the initial clarity and precision criteria of (P2). In other words, it seems that (P2) is either trivially true but liable to being misunderstood or it endorses a substantive account of logic that rules out some of what should count as permissible areas of analytic exploration.

This brief criticism of (P2) brings to view an important strength we identified in the definition of analytic feminism found in the previous section; namely, that it was compatible with a wide range of philosophical tools. I take it that such a result is indeed very desirable. Accordingly, we can set the following as a constraint on the adequacy of a putative definition of analytic theology:

AC1 - Avoid overly restrictive methodological components and trivial characterizations of the method. ${ }^{22}$

Let us now set aside these methodological reflections and consider a more socially-shaped way of defining analytic theology.

${ }^{20}$ See Beall, "Christ - A Contradiction" from whom I take the above problem of Christology and Aaron J. Cotnoir, "Theism and Dialetheism," Australasian Journal of Philosophy 96, no. 3 (2017): 592609, who examines some classic theological puzzles - e.g. the paradox of the stone-and considers how dialetheism might dissolve such paradoxes.

${ }^{21}$ This maybe more pithy than precisely accurate. There is still a universalizable true LOGIC if Beall, "Christ" is correct. The difference is that on that account, it isn't a logic that presupposes whether the domain of inquiry in question is glutty (i.e. allows for true contradictions) or gappy (i.e. allows for propositions to be neither true nor false).

${ }^{22}$ I do not think it is possible to provide an unproblematic recipe for determining what methodological components count as overly restrictive. Nevertheless, even without some sort of guide, we can still identify clear cases of overly restrictive components and offer arguments for excluding other, lessclearly-overly-restrictive components. 
In an attempt of highlighting the social expediency of using the term 'analytic' Oxford theologian William Wood writes,

[Though] there is no sharp distinction between analytic theology and analytic philosophical theology...the label "analytic theology" functions as a quick and easy way of letting one know the nature of this particular kind of inquiry: it features certain presuppositions and assumptions but not others; it features a certain kind of writing; it appeals to some intellectual influences and interlocutors but not others; it similarly presupposes a certain set of intellectual villains, and so on. The label "analytic theology" is better than the more venerable label of "philosophical theology" as a shorthand description for that kind of inquiry. It is better because it is more specific. ${ }^{23}$

From this brief paragraph, Wood seems to indicate that the meaning of 'analytic theology', or rather what is communicated when someone self-identifies as an analytic theologian, is at least a set of assumptions concerning the background of that individual; that is, assumptions about who that person reads, does not read, how that person writes, etc. Whether or not including such assumptions in a definition of analytic theology would be a good thing, however, is questionable.

Of course, we ought to concede that undoubtedly Wood is right that such assumptions about the ideological portfolio of an analytic theologian characterize assumptions many of us make about analytic theologians. Indeed, he is also correct that there is a degree of expediency in using the label 'analytic' in front of 'theology' in many contexts. ${ }^{24}$ Despite this, however, it seems that we should be careful, given the contingency of such facts, about allowing these assumptions concerning the likely intellectual development and interests of a given analytic theologian to enter into a definition of analytic theology without careful qualification.

For instance, is it essential to the practice of analytic theology that it flows from the ideas of Russell, Moore, Frege and Wittgenstein through those ideas found in Plantinga and Wolterstorff ${ }^{25}$ ? Presumably not, for it does not seem impossible to imagine that we might someday run into Martians doing theology (even Christian theology) of a strikingly analytic sort. Must we then suppose that we

\footnotetext{
${ }^{23}$ Wood, "Analytic Theology as a Way of Life," 45.

${ }^{24}$ In a more recent article-William Wood, "Trajectories, Traditions, and Tools in Analytic Theology," Journal of Analytic Theology 4 (2016): 254-266-Wood argues that analytic philosophy should be understood as an intellectual tradition and that this accounts for various difficulties philosophers have concerning how to engage with theology. This differs from my own account insofar as I argue that, to use Wood's language, the formal model of philosophy is not subsidiary to a substantive model. In other words, I do not share Wood's skepticism of the existence of a formal method (and use of this method) distinctive of analytic philosophy.

${ }^{25}$ William J. Abraham, “Turning Philosophical Water into Theological Wine," Journal of Analytic Theology 1, no. 1 (2013): 8, also considers the possibility of seeing analytic theology as necessarily deriving from Alvin Plantinga.
} 
can call their work 'analytic' only if it is causally connected back to the beginnings of analytic philosophy on earth? I would hope not. ${ }^{26}$

Thus, it seems that although there may indeed be expediency in including socially-shaped components in one's description of analytic theology, such components cannot be essential to the practice of analytic theology. In order to allow for the expediency of such socio-historical components, then, I suggest that we flag them as assumptions that are defeasible; that is, as assumptions that can be undermined by learning further information about the purported practitioner or work of analytic theology in question. Such undermining of the assumptions, on this view, would not preclude the practitioner or work from inclusion in analytic theology. But they would allow those coming to the project of analytic theology to more easily recognize analytic theology, or analytic theologians, when they see them. ${ }^{27}$ This brings us to a second adequacy constraint for defining analytic theology:

AC2 - Flag any socio-historical components of a description of analytic theology as contingent and defeasible. ${ }^{28}$

Yet another way of defining analytic theology can be found in the writings of William J. Abraham who writes,

${ }^{26}$ As an anonymous referee has helpfully pointed out, someone might nevertheless bite the bullet on this point and claim that the Martians I have imagined are in fact not analytic theologians despite bearing a certain family resemblance to the analytic theologians found on Earth with respect to methodology. A full discussion of family resemblance accounts would take us too far afield for the purposes of this article, but briefly I can at least say this: I am skeptical that family resemblance can function as a bottom level notion. If two sets of people bear some family resemblance, I take it that there should be some property or part in virtue of which it is true that they bear a family resemblance. And if so, it seems that such family resemblances are not fundamental, but rather, derivative of those properties or parts in virtue of which they hold.

${ }^{27}$ Why is this helpful? Well, consider someone who defines human beings by saying they are all featherless bipeds. Perhaps that is actually true, but it may not be essential to humankind as such (i.e. it may not be essential that humans lack feathers and walk on two feet). In other words, it might be a contingently but also universally true statement about humankind. The point, then, is this: the socialdefinition going into analytic theology does not quite get up to universal truth, perhaps, but it is similar to 'featherless biped' as a means of picking out the thing under question, even if not quite getting at the essence of the thing.

${ }^{28}$ What is really happening here is a bit of a give-and-take between defining 'analytic theology' by description or by reference. The latter view would fit better with the socio-historical definition, but 'analytic theology' unlike certain proper names (e.g. 'Sarah Coakley') seems to fit less well with this Saul Kripke, Naming and Necessity (Cambridge, MA: Harvard University Press, 1980) reference position. Rather, if someone asks the question, "What makes analytic theology analytic?", they are typically looking for some sort of description that explains the aptness of 'analytic' as an adjective rather than a referent in the Kripkean sense. 
Analytic theology can usefully be defined as follows: it is systematic theology attuned to the deployment of the skills, resources, and virtues of analytic philosophy. It is the articulation of the central themes of Christian teaching illuminated by the best insights of analytic philosophy. ${ }^{29}$

This definition of Abraham's has for many practitioners of analytic theology from the philosophers' side become somewhat of a slogan: analytic theology is theology informed by analytic philosophy. While true to some extent, this definition seems wrongheaded (i.e. if we ignore the question of what skills and resources actually characterize analytic philosophy in the first place). And it seems wrongheaded precisely insofar as we say nothing more about theology's influence on analytic philosophy. Recall that in her attempt at a definition of analytic feminism, Ann E. Cudd carefully defined analytic feminism as a two-way street. Indeed, Oliver Crisp in an interview with the editors of one academic journal characterizes analytic theology similarly:

How can bridges be built between analytics and theologians that might be mutually beneficial and that might mean there is more traffic between the two disciplines? That is an important question, I think. And it is not all one-way traffic, either. There is important theological work that analytics can benefit from... ${ }^{30}$

The addition of mutual benefit to this characterization of analytic theology is, I think, essential to any definition. Otherwise, the definition takes on the appearance of an ideological colonialism, whereby the analytic philosophers seek to take over the territory of theology from their non-analytic counterparts. Colonialism is not a promising way forward, and I doubt that more than a few analytic theologians would endorse such a position. Thus, we have our third adequacy constraint on a definition of analytic theology:

AC3 - Ensure that the definition allows for insights from non-analytic approaches to theology to influence the analytic method employed in ways that further the theological task.

Now, there are many other possible definitions of analytic theology that we could consider, but in light of the three adequacy constraints given and reflections from the previous section on analytic feminism, let us turn to a delineation of some desiderata for a provisional definition of analytic theology.

3. Understanding the 'Analytic' in Analytic Theology

${ }^{29}$ Abraham, "Systematic Theology," 54.

${ }^{30}$ Oliver D. Crisp, “Analytic Theology: Interview with Editors Crisp and Rea." Conducted for the blog for the Evangelical Philosophical Society (2010): Available online at http://blog.epsociety.org/2010/01/analytic-theology-interview-with.asp, accessed 23 August 2018, and quoted in Joshua R. Farris and James M. Arcadi, "Introduction to the Topical Issue 'Analytic Perspectives on Method and Authority in Theology'," Open Theology 3 (2017): 630-632. 
Allow me now to string together some important points from the previous two sections. First, let us bring together all three of the adequacy constraints from our discussion of ways to define analytic theology above. The constraints were these:

AC1 - Avoid overly restrictive methodological components and trivial characterizations of the method.

AC2 - Flag any socio-historical components of a description of analytic theology as contingent and defeasible.

AC3 - Ensure that the definition allows for insights from non-analytic approaches to theology to influence the analytic method employed in ways that further the theological task.

In addition to these constraints, we can enumerate roughly five desiderata for a definition of the 'analytic' in analytic theology from our discussion of analytic feminism. These desiderata claim that a good definition should...

D1 - allow analytic theologians to identify with both their analytic leanings and the theological task;

D2 - not include problematic biases (e.g. masculinism or anti-Continentalism) ${ }^{31}$;

D3 - permit...(i) a wide range of methodological tools [i.e. as in AC1]; (ii) the legitimacy of social groups as subjects for discourse [e.g. in the case of theology, the church]; (iii) embodied experience to be included as not-wholly-propositional evidence or a way of evaluating/construing that to which one's evidence connects ${ }^{32}$; and (iv) recognition of a degree of social construction with respect to various concepts of study [i.e. with the caveat that the contingency of such features would make the qualification of AC2 relevant].

D4 - suggest that the best way to pursue the theological task is by pursuing truth, objectivity, rationality, justice, and the good ${ }^{33}$;

\footnotetext{
${ }^{31}$ In this paper I have mostly ignored the analytic-continental distinction. I do not ignore it because I think there is nothing distinctive of continental or analytic approaches to philosophy; nevertheless, those distinctions do seem difficult to draw in any sort of uncontroversial way. Whatever we say about the relationship between continental and analytic methods, I take it that someone can adopt an analytic (perhaps also non-continental) method without being anti-continental.

32 See, for instance, the reflections of Sarah Coakley, Powers and Submissions: Spirituality, Philosophy and Gender (Oxford Blackwell Publishing, 2002) and Sarah Coakley, "Feminism and Analytic Philosophy of Religion," in The Oxford Handbook of Philosophy of Religion, ed. William J. Wainwright (Oxford: Oxford University Press, 2007), 494-525.

${ }^{33}$ D4 comes directly from the second paragraph of Cudd, "Analytic Feminism," 157-159's definition of analytic feminism, except that I removed 'logical consistency' from the list for reasons already given
} 
D5 - express its practitioners' engagement with the literature of analytic philosophy, non-analytic philosophy (or theology) as well in varying degrees, and their desire to work with theologians of other methodological persuasions in furthering the theological task. ${ }^{34}$

With these various desiderata and constraints, I propose the following as a provisional definition of analytic theology modeled in part on the definition of analytic feminism provided by Ann E. $\mathrm{Cudd}^{35}$ (albeit a definition that leaves open much concerning the nature of the theological task).

Analytic theology applies analytic (though not exclusively analytic) concepts and methods to theological issues and applies theological concepts and insights to issues that have traditionally been of interest to analytic philosophers. Although the analytic concepts and methods under question are wide ranging, they include the utilization of logical and linguistic analysis and are read typically, though not essentially, against a background philosophical literature roughly beginning with the likes of Frege, Russell, Moore, and Wittgenstein. Moreover, analytic theology recognizes the importance of (i) allowing its practitioners to include both non-propositional items in the set of theological data and groups as possible subjects of discourse, as well as (ii) accommodating the social construction of a number of concepts that are important to the theological task with some notable exceptions such as the concepts of truth, objectivity, rationality, justice, and the good.

The above three-sentence definition carefully incorporates all of AC1-3 and D1-5, and it is worth reflecting briefly on how it does so. The first sentence encapsulates AC3 and D1, and the parenthetical comment aims to eliminate any concerns of bias against non-analytic thought (i.e. as in D2). The second sentence incorporates the first conjunct of D3 and AC1, both of which stress that we not define the methodological tools of analysis too narrowly. In addition, the second sentence explicitly mentions an acquaintance with a particular philosophical literature and history mentioned by D5 while carefully flagging the defeasibility of that literature and history in accordance with AC2. Lastly, the third sentence incorporates what remains; that is, the second, third, and fourth conjuncts of D3 as well as D4. The third sentence achieves this by explicitly mentioning the inclusion of nonpropositional items, group ontology, and social construction (i.e. D3ii-iv) while explicitly highlighting exceptions to the social construction point brought out in D4. In this way, then, we have before us a

in my discussion of Rea's prescription 2 of analytic philosophy. Moreover, I use the term 'suggest' here to emphasize that this is a research program of sorts that is not dogmatically beholden to some sort of strong claim to infallibly know what the best way to pursue the theological task is.

${ }^{34}$ D5 also comes from the second paragraph of the passage quoted above in Cudd, "Analytic Feminism" with a bit of the content changed around to reflect its application to analytic theology as opposed to analytic feminism.

${ }^{35}$ Cudd, "Analytic Feminism" 
new definition of analytic theology which overcomes the previously intractable shortcomings of previous definitions.

\section{Conclusion}

In this paper, we have seen that defining the 'analytic' in analytic feminism and analytic theology is not a straightforward task, and this irony has not been lost on those who accept that label. Nevertheless, we have seen that there are several positive reasons for someone to identify as an analytic theologian or analytic feminist, primarily having to do with a degree of methodological transparency and identification with one's background and commitments-i.e. whether feminist, theological, or analytic. The above definition (one I offer provisionally) allows practitioners of analytic theology in particular to identify with both their analytic and theological commitments without drawing methodological borderlines prematurely. It also allows that the subject matter of theology might inform the philosophical methodology, such that analytic theology is identified as a two-way street. Furthermore, as our reflections on the history of analytic feminism reveal, such a feature is crucial for a definition of analytic theology to maintain plausibility. I offer this definition, then, as an important step forward in the discussion of the plausibility of analytic theology; that is, one built upon, despite sometimes respectfully departing from, the foundations of its predecessors. ${ }^{36}$

\footnotetext{
${ }^{36}$ I would like to thank Christa McKirland (the director of Logia at the University of St Andrews) for providing me an opportunity to write and present this material in an earlier form. The feedback from that seminar was immensely helpful, thanks are due in particular to Bruce Benson, Joshua Cockayne, Aaron J. Cotnoir, Hannah Craven, Christa McKirland, Jeremy Rios, and Alan J. Torrance. I would also like to thank two anonymous referees whose supererogatory feedback resulted in a much better paper. Lastly, I would especially like to thank the Templeton Religion Trust whose generous funding created an environment in which I had sufficient time to dedicate to this project.
} 